\title{
Creation of Ship Navigation Data Using Simulation Technology in Training Module
}

\author{
Zulkifly Bin Mat Radzia, Tang Jut Weng ${ }^{b}$, \\ Md Hafize Md Eusoff ${ }^{b}$, Sarah Isnan ${ }^{b}$, Adenen Aziz ${ }^{b}$
}

All ships need navigation data to ensure they stay on track during course-changing maneuvers. Navigation data are usually obtained by shipyards while conducting turning trials at sea. The aim of this research was to generate navigation data for warships, such as the Leander Class Frigate (LCF). The research was conducted using the Ship Bridge Simulator (SBS) simulation technology at the Maritime Centre of the National Defence University of Malaysia (NDUM). Turning trials were conducted at various speeds, rudder angels, and heading changes. Distance to new course, advance and transfer have been tabulated for LCF navigation data. Navigation experts validated the data by nautical chart plotting. The data were found to be highly reliable for the training module. The research was successfully conducted and generated LCF navigation data. The navigation data collected

\section{KEY WORDS}

$\sim$ Navigation data

$\sim$ Turning trial

$\sim$ Simulation technology

$\sim$ Ship bridge simulator

$\sim$ Training module

a. MAREC, National Defence University of Malaysia

e-mail: zulkifly@upnm.edu.my

b. Universiti Pertahanan Nasional Malaysia, Kuala Lumpur, Malaysia

e-mail: hafize@upnm.edu.my

doi: 10.7225/toms.v10.n02.w03

This work is licensed under (cc) BY

Received on: 20.05.2021/Revised on: 18.06.2021/Accepted on: 06.07.2021/Published online: 16.07.2021 are highly accurate and effective for the naval cadet navigation training module at the NDUM. The SBS software is highly suitable for turning trials and navigation data generation.

\section{INTRODUCTION}

Maritime transportation is essential for the commercial sector, especially for a maritime nation. The international rules and regulations for ships at sea are coordinated by the International Maritime Organisation (IMO) and required to be observed by all ships at sea (Cockcroft, 2004). Although a variety of instruments can be used for navigation purposes, vessels need accurate navigation data to maintain navigation safety. In order to train naval cadets in navigation safety, the National Defence University Malaysia (NDUM) had procured a full-mission Ship Bridge Simulator (SBS) from Kongsberg, Norway in 2015 (Zulkifly, 2016). Thereafter, a training module known as the LAKSANA Module was developed to improve professional competencies of naval cadets. The LAKSANA Module contains psychomotor and affective curriculum for naval cadets' assessment. However, the LAKSANA Module has yet to establish the navigation data for different types of ships in the SBS. Therefore, the objective of this research was to generate ship navigation data for Leander Class Frigates (LCF) using SBS simulation technology at the NDUM Maritime Centre.

Ships need navigation data to ensure they stay on track during course-changing maneuvers (Hirano, 1980). The captain is required to procure such data prior to setting sail. Without navigation data the captain would not be able to maneuver his vessel precisely when changing course (Drachev, 2012), increasing the risk of collision or even grounding at sea. Figure 1 shows the turning circle of a ship and the terms used in navigation practice. 


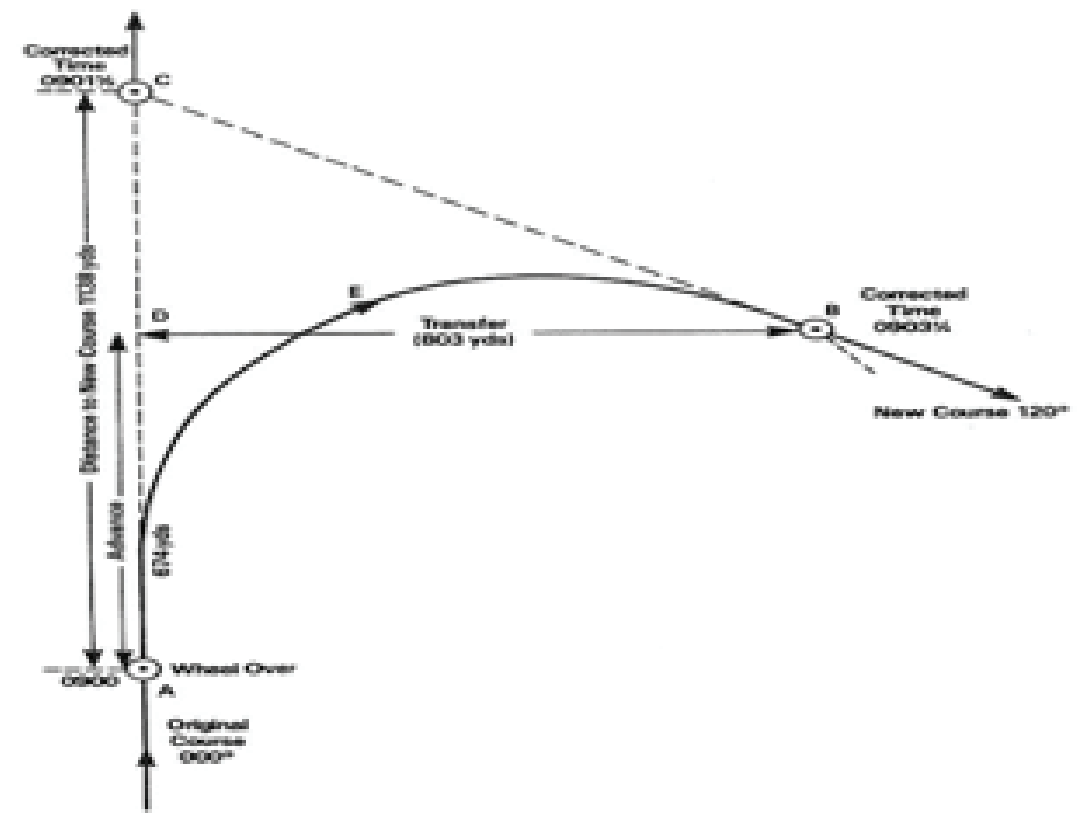

Figure 1.

Ship's turning circle and navigation terms used in navigation practice.

(Admiralty Manual of Navigation Volume 1, BR45, 1987).

- Distance to New Course (AC) is the distance from the wheel over position to the point of intersection of the original course and the new course of a ship.

- $\quad$ Advance (AD) is the distance a ship has advanced in the direction of the original course and on completion of a turn measured from a wheel over position.

- Transfer (DB) is the distance of a ship's transfer in a direction at an angle from the original course to the new course.

Figure 2 shows heading change from $351^{\circ}$ to $114^{\circ}$ required to enter the Lumut harbor. Point $A$ is the start of the turn at wheel over position and Point $B$ is the start of the new course. Point $C$ is the point of intersection of the original course and the new course. The distance between points $A$ and $C$ is distance to new course (DNC), between points $A$ and $D$ the advance (ADV) and between points $B$ and $D$ the transfer (TRANS). Nautical chart plots are based on the navigation data of His Majesty's Ship (KD) HANG TUAH from Table 1.

The NDUM SBS was built based on a Royal Malaysian Navy (RMN) training vessel used for naval cadet navigation training. The SBS build-up depicts a ship bridge with windows, fitted with navigation equipment such as the wheel, throttle, radar, electronic chart, communication equipment, ship's data board and the captain's chair. The navigation equipment was integrated using computer software capable of displaying the view of ports, straits and coastal areas. Jyotsna Pandey (2016) said that mathematical models could be used in computer software to generate ship navigation data with great accuracy. Figure 3 is an illustration of the SBS at the NDUM Maritime Centre acquired in 2015 from Kongsberg, Norway.

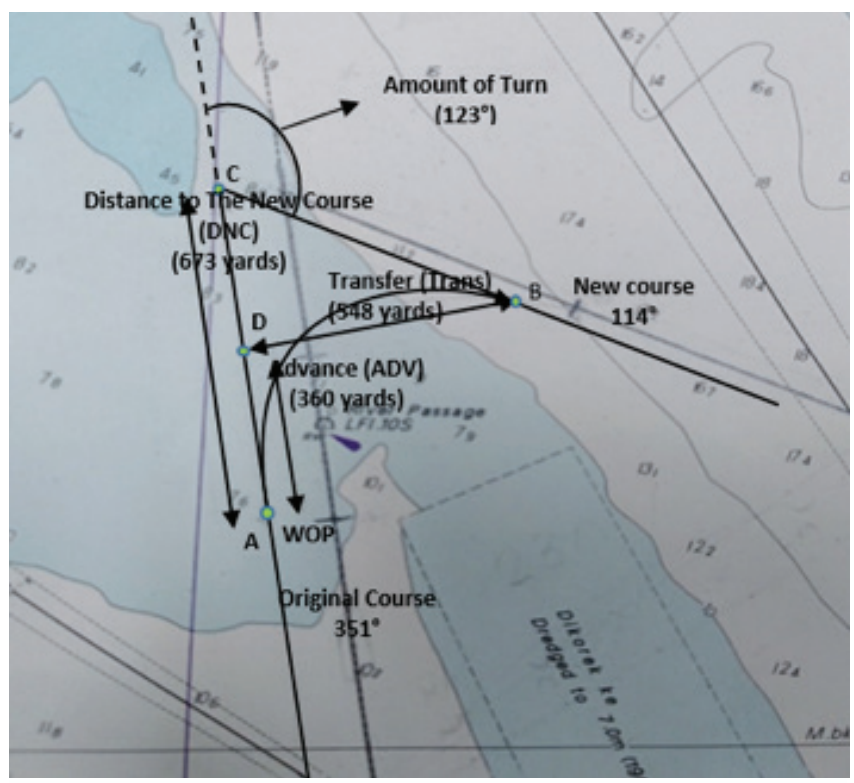

Figure 2.

Ship's navigation data drawn on nautical chart. 
Table 1.

Extract from KD HANG TUAH navigation data.

\begin{tabular}{llllll} 
Speed & Rudder Angle & Angle of Turn & ADV (cable) & TRANS (cable) & DNC (cable) \\
\hline 10 knots & $20^{\circ}$ & $123^{\circ}$ & 360 yards (1.8) & 548 yards (2.8) & 673 yards (3.4) \\
\hline
\end{tabular}

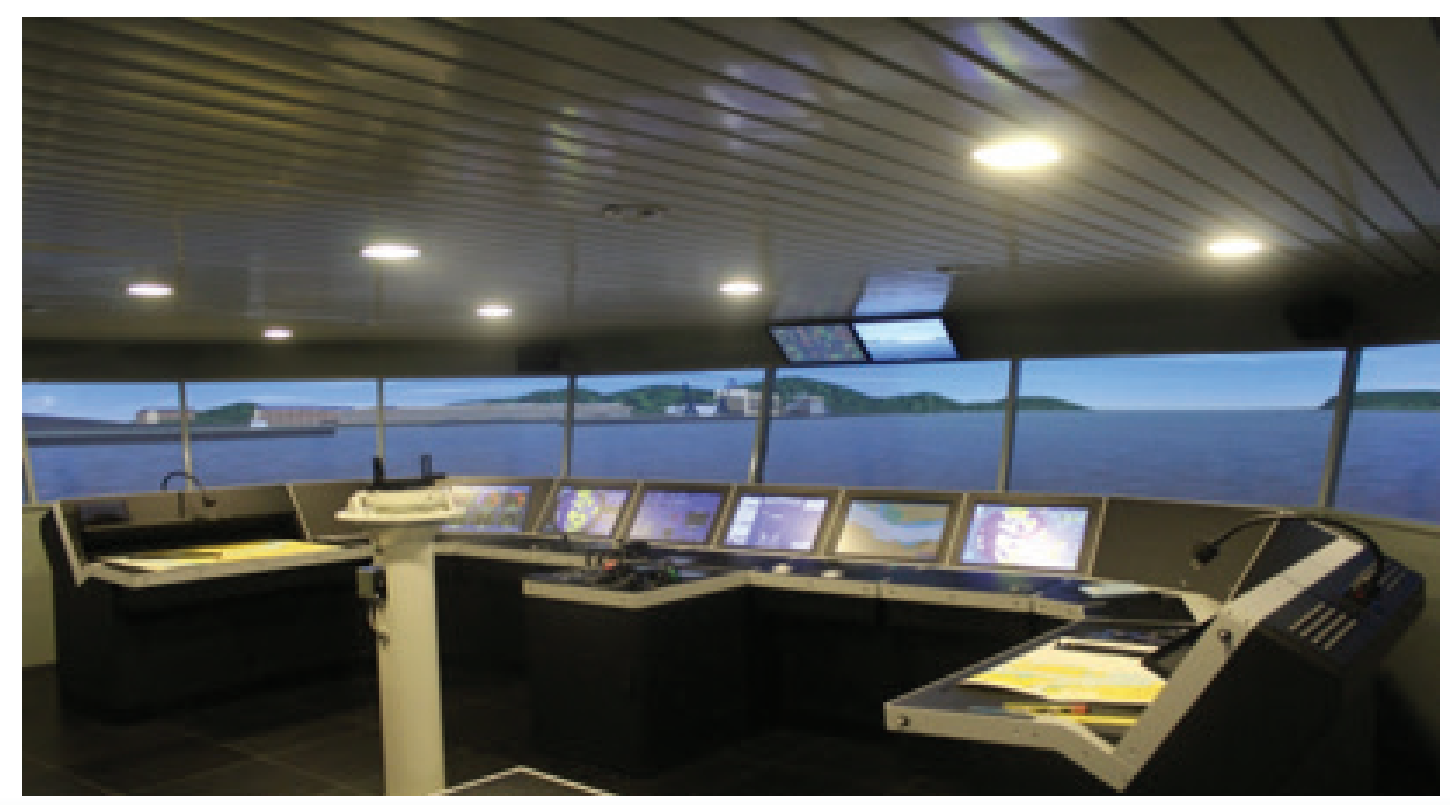

Figure 3.

The SBS at Maritime Centre, UPNM (Zulkifly, 2016).

The LAKSANA Module was developed based on SBS capabilities that can be used to assess the levels of the psychomotor and affective domains, as well as the competencies of naval cadets. The seven levels of the psychomotor domain are: perception, set, guided response, mechanism, complex overt response, adaptation and origination. The five levels of the affective domain are: receiving phenomena, responding to phenomena, valuing, value organisation and value internalisation. A simulator is an effective navigation training tool for the development of psychomotor and affective domains in naval cadets (Zulkifly, 2016). The SBS can adapt, slow down, fast track or repeat scenarios depending on the performance of individual trainees. Naval cadets are required to undergo navigation training that will enable them to enter or leave the harbor, deal with man overboard recovery situations, pilot to anchorage, execute fleet maneuvering exercises and evolutions at sea using the SBS. The professional conduct of the LAKSANA
Module requires the navigation data of the vessel used in the training module to be developed.

\section{METHODOLOGY}

A simulation technique that uses a mathematical model is an effective method for predicting a vessel's maneuvering ability (Etter, 2013). The goal of this research was to generate navigation data for the LCF, to be used by naval cadets in their navigation training module. The primary data will be generated using the ship's turning circle trials conducted at the SBS. The LCF model will be used for the turning trials due to the similarity of the maneuvering capabilities of the LCF and the KD HANG TUAH. Navigation data generated have been validated by former RMN ship commanding officers who are serving as lecturers at the NDUM. Analysis was conducted through comparison with the KD HANG TUAH navigation data, serving as secondary data. Navigation data collected from the turning trials conducted in the SBS are transformed into a table and graph for final analysis. 


\section{RESULTS AND ANALYSIS}

Navigation data have been validated through interviews with three navigation experts. All three respondents are former commanding officers of RMN ships who have conducted turning trials of their vessels. They said that officers of the watch and commanding officers need navigation data as a reference, to familiarize themselves with the turning capabilities of their vessel. Navigation data are normally acquired through the turning trials of the vessel conducted by the shipyard. However, turning trials need to be repeated for verification purposes by a ship's commanding officer. External factors, such as ocean currents, tidal streams and the wind need to be considered to determine the accuracy of navigation data. These external factor predictions are extracted from tide tables and nautical charts.
The exact maneuvering capability of a vessel cannot be determined without accurate navigation data. The SBS used in LCF turning trials is appropriate because naval cadets need to be trained onboard a frigate class warship. Naval cadets are required to use a frigate's DNC, TRANS and ADV accurately during the LAKSANA Module training to avoid grounding and collision of ships at sea.

Navigation data generated through LCF turning trial simulation, which produced various DNC, ADV and TRANS, are recorded in Table 2. Table 2 suggests that the bigger the rudder angle used, the shorter the transfer, advance and distance to new course, since a vessel's turning circle is smaller when a greater rudder angle is used.

Table 2.

LCF navigation data recorded at SBS at the speed of 10 knots.

\begin{tabular}{|c|c|c|c|c|c|c|c|c|c|c|c|c|}
\hline \multirow{3}{*}{$\begin{array}{l}\text { Rudder } \\
\text { Angle }\end{array}$} & \multicolumn{12}{|c|}{ Change of Heading SBS } \\
\hline & \multicolumn{3}{|l|}{$45^{\circ}$} & \multicolumn{3}{|l|}{$60^{\circ}$} & \multicolumn{3}{|l|}{$90^{\circ}$} & \multicolumn{3}{|l|}{$120^{\circ}$} \\
\hline & DNC & ADV & TRANS & DNC & ADV & TRANS & DNC & ADV & TRANS & DNC & ADV & TRANS \\
\hline $10^{\circ}$ & $\begin{array}{l}475 \\
(2.4)\end{array}$ & $\begin{array}{l}722 \\
(3.6)\end{array}$ & $\begin{array}{l}241 \\
(1.2)\end{array}$ & $\begin{array}{l}590 \\
(3.0)\end{array}$ & $\begin{array}{l}820 \\
(4.1)\end{array}$ & $\begin{array}{l}395 \\
(2.0)\end{array}$ & $\begin{array}{l}909 \\
(4.5)\end{array}$ & $\begin{array}{l}909 \\
(4.5)\end{array}$ & $\begin{array}{l}745 \\
(3.7)\end{array}$ & $\begin{array}{l}1449 \\
(7.2)\end{array}$ & $\begin{array}{l}778 \\
(3.9)\end{array}$ & $\begin{array}{l}1166 \\
(5.8)\end{array}$ \\
\hline $15^{\circ}$ & $\begin{array}{l}366 \\
(1.8)\end{array}$ & $\begin{array}{l}574 \\
(2.9)\end{array}$ & $\begin{array}{l}207 \\
(1.0)\end{array}$ & $\begin{array}{l}462 \\
(2.3)\end{array}$ & $\begin{array}{l}670 \\
(3.4)\end{array}$ & $\begin{array}{l}359 \\
(1.8)\end{array}$ & $\begin{array}{l}709 \\
(3.5)\end{array}$ & 709 & & & & \\
\hline (3.5) & $\begin{array}{l}610 \\
(3.1)\end{array}$ & $\begin{array}{l}1129 \\
(5.6)\end{array}$ & $\begin{array}{l}635 \\
(3.2)\end{array}$ & $\begin{array}{l}859 \\
(4.3)\end{array}$ & & & & & & & & \\
\hline $20^{\circ}$ & $\begin{array}{l}345 \\
(1.7)\end{array}$ & $\begin{array}{l}503 \\
(2.5)\end{array}$ & $\begin{array}{l}159 \\
(0.8)\end{array}$ & $\begin{array}{l}416 \\
(2.1)\end{array}$ & $\begin{array}{l}586 \\
(2.9)\end{array}$ & $\begin{array}{l}290 \\
(1.5)\end{array}$ & $\begin{array}{l}650 \\
(3.3)\end{array}$ & $\begin{array}{l}650 \\
(3.3)\end{array}$ & $\begin{array}{l}547 \\
(2.7)\end{array}$ & $\begin{array}{l}1004 \\
(5.0)\end{array}$ & $\begin{array}{l}541 \\
(2.7)\end{array}$ & $\begin{array}{l}798 \\
(4.0)\end{array}$ \\
\hline
\end{tabular}

Note: DNC, ADV and TRANS are measured in yards (cable)

In Figure 4, LCF's course in the SBS simulation was plotted for $000^{\circ}$, speed of 10 knots and a $15^{\circ}$ rudder angle. The DNC is measured from $A$ to $C, A D V$ from $A$ to $D$ and TRANS from $B$ to $D$ to generate LCF navigation data. Turning trials have been conducted at various rudder angles and heading changes, as shown in Table 2.

Meanwhile, the reliability of the navigation data obtained during the LCF turning trials was checked by second year undergraduate students of Maritime Technology (BSC. MarTech). Navigation data reliability was verified through the use of the data in practical exercises in the LAKSANA Module. The navigation data were plotted by students showing LCF DNC, ADV and TRANS on the nautical chart. The LCF navigation data were found to be highly accurate when used by students in the LAKSANA Module. Navigation experts have conducted a qualitative analysis of the LCF navigation data and confirmed that the data could be used to train naval cadets in pilotage, man overboard recovery and fleet maneuvering exercises. Navigation experts recommended that the data be used by naval cadets in the LAKSANA Module. BSc. MarTech students agreed that the LCF navigation data were reliable for accurate plotting on the nautical chart and pilotage exercises at the SBS. Navigation data were found to be an effective tool for improving the navigational competencies of naval cadets before undergoing industrial training onboard RMN ships. 


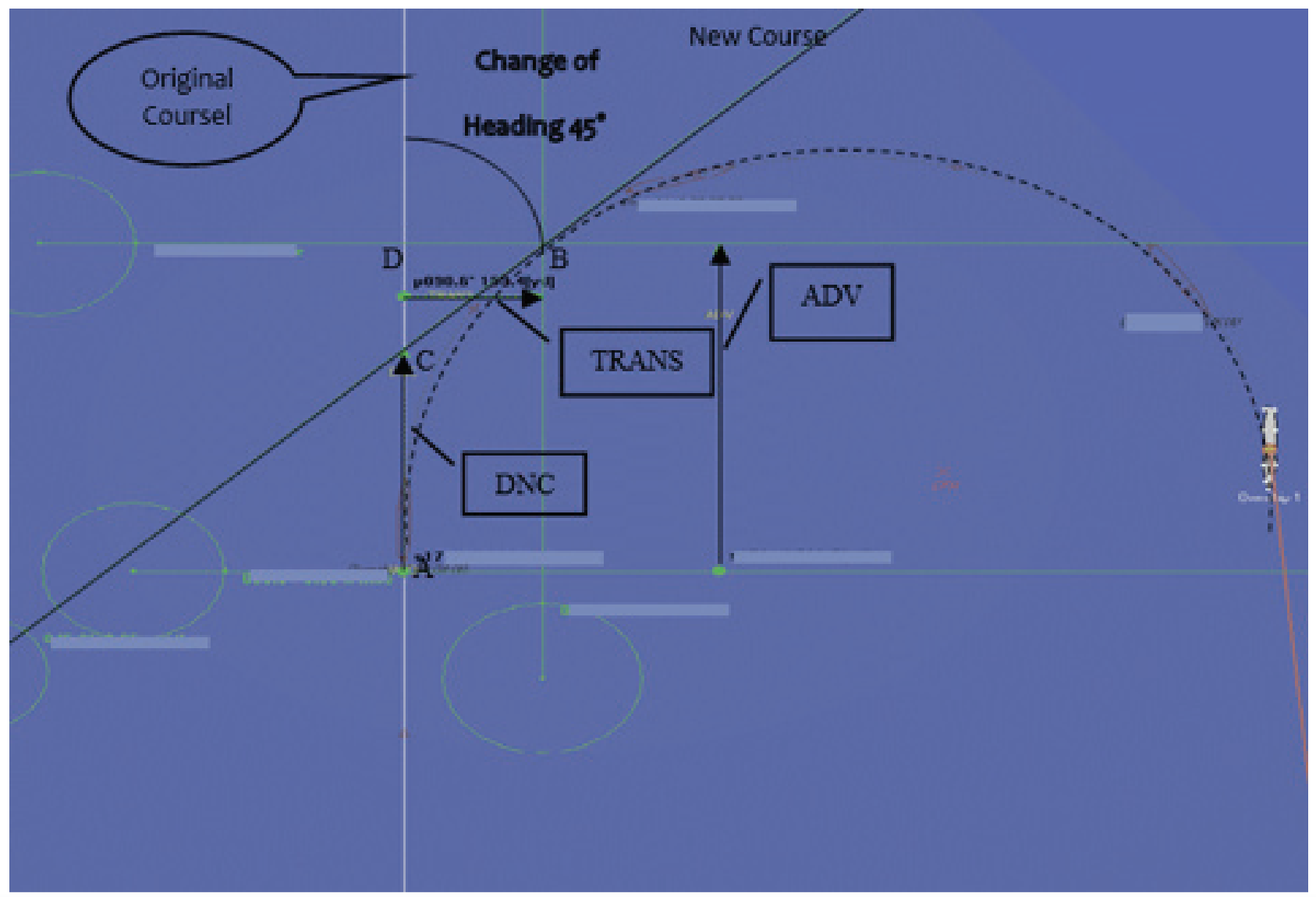

Figure 4.

LCF turning trail course at the SBS.

\section{CONCLUSION}

This research has successfully generated LCF navigation data for the LAKSANA Module. The SBS was found to be suitable for the creation of navigation data to be used in the pilotage training of naval cadets. The creation of LCF navigation data had a huge impact on the development of competencies that naval cadets need to make a headway in the navy. SBS software simulation was found to be suitable for conducting turning trials and generating a vessel's navigation data. Navigation experts from the ranks of former RMN ship commanding officers, who are NDUM lecturers, have validated the LCF navigation data and confirmed their suitability for the LAKSANA Module. The reliability assessment done by BSc, MarTech students confirmed that the navigation data are highly accurate for measuring LCF's DNC, ADV and TRANS. Hence, this research is a contribution in the field of creation of vessel navigation data using SBS simulation technology at the NDUM Maritime Centre.

\section{REFERENCES}

Cockcroft, F., 2004. Seamanship and Nautical Knowledge. Glasgow: Brown, Son \& Ferguson.Ltd.

Drachev, V., 2012. Calculating Wheel-Over Point. Asia-Pacific Journal of Marine Science \& Education, 2(1).

Etter, P., 2013. Underwater Acoustic Modeling and Simulation. USA: CRC Press.

Greswell, J.W \& Greswell, J.D., 2018. Research Design Qualitative, Quantitative and Mixed Method 5th Ed. USA: Saga Publication.

Hebbs, R., 2017. Naval Science III. Annapolis: Naval Institute Press.

Hirano, M.T., 1980. Ship Turning Trajectory in Regular Wave. Trans. Tokyo: Jpn. Soc. Nav. Archit. 60

Jyotsna Pandey, K.H., 2016. Study on Turning Maneuver of Catamaran Surface Vessel with a Combined. Conference on Control Applications in Marine Systems, Trandheim, Norway: IFAC CAMS 2016, pp. 446-451.

Ministry of Defence, UK, 1983. Admiralty Manual of Seamanship, BR67 Vol 3. London: Her Majesty's Stationery Office. 
Ministry of Defence, UK, 1987. Admiralty Manual of Navigation, BR45 Vol 1. London: Her Majesty's Stationery Office.

Ministry of Defence, Malaysia, 2019. Defence White Paper, Kuala Lumpur: MoD Malaysia.

National Security Council, Malaysia, 2019. National Security Policy, Putrajaya: NSC, Malaysia.
Stravridis, J., 2010. Command at Sea. 6th ed. Annapolis: United States Naval Institute.

Tanaka, Y., 2018. The International Law of the Sea, 3rd ed. Cambridge: Cambridge University Press.

Zulkifly, M.R., 2016. Module Psikomotor dan Afektif Menggunakan Teknologi Simulator. Kuala Lumpur: UPNM. 